\title{
Serum Lipid Profile in Early Pregnancy as a Predictor of Preeclampsia
}

\author{
Singh U,Yadav S, Mehrotra S, Natu SM, Kumari K, Yadav YS \\ Dr Urmila Singh ${ }^{1}$ M D, Dr Sonali Yadav ${ }^{2}$ Ph.D, Dr Seema Mehrotra ${ }^{1}$ M D, Dr S M Natu ${ }^{2}$ Ph D, Dr Kamlesh kumari ${ }^{1}$ M D, \\ Dr Yogendra Singh Yadav M D
}

Department of Obstetrics and Gynecology ${ }^{1}$, Department of Pathology ${ }^{2} \&$ Department of Paediatrics ${ }^{3}$, King George’s Medical University, Lucknow, Uttar Pradesh, India.

Address for correspondence: Dr Urmila Singh, Email: drsingh.urmila@gmail.com

\begin{abstract}
Background: The study aimed to investigate the relationship between early pregnancy serum lipid concentrations and risk of preeclampsia. Material and Methods: Serum lipid profile was measured enzymatically by standardized assay in 270 pregnant women between 13-20 weeks of gestation. Out of these total number 58 subjects developed preeclampsia (study group) while 212 subjects remained normotensive (control group). Results: The mean serum level of total cholesterol (TC), triglycerides (TG), low density lipoprotein cholesterol (LDL-C) and very low density lipoprotein cholesterol (VLDL-C) was significantly higher in preeclamptic women as compared to normotensive pregnant women. While preeclamptic women showed significant fall in high density lipoprotein cholesterol HDL-C) level as compared to normal pregnant women. Conclusion: The measurement of serum lipid profile in early pregnancy may serve as early predictor of preeclampsia.
\end{abstract}

Key words: Dyslipidemia, Lipid profile, Preeclampsia, Pregnancy

\section{Introduction}

Preeclampsia is a pregnancy specific disorder, characterized by pregnancy induced hypertension (BP $\geq 140 / 90 \mathrm{~mm} \mathrm{Hg}$ ) on two occasion, atleast 6 hours apart and proteinuria of $\geq 300 \mathrm{mg} / 24$ hours or $\geq 1+$ dipstick after 20 weeks of gestation in previous normotensive women. It occurs in about $2-8 \%$ of pregnancies ${ }^{1,2}$. It is the most common medical complication of pregnancy, whose incidence has continued to increase worldwide. It is associated with significant maternal morbidity and mortality, accounting for about 50,000 deaths worldwide annually ${ }^{3,4}$ and risk is very high in Indian women ${ }^{5}$. There is no clear distinction between normotensive and preeclamptic pregnancies in terms of pathogenic factors and disease mechanisms ${ }^{6}$.

Manuscript received: $15^{\text {th }}$ June 2013

Reviewed: $16^{\text {th }}$ June 2013

Author Corrected; $29^{\text {th }}$ June 2013

Accepted for Publication: $30^{\text {th }}$ June 2013
However, various factors are implicated in the pathogenesis of preeclampsia including genetic, immune, vascular, and oxidative stress ${ }^{7}$. Maternal serum lipids are significantly elevated during pregnancy ${ }^{8-11}$.

Women who develop preeclampsia experience even more dramatic lipid changes. Most, studies have shown a preeclampsia-dyslipidemic pattern of increased triglycerides, cholesterol, low density lipoprotein cholesterol (LDL-C), and decreased high-density lipoprotein cholesterol (HDL-C) concentrations ${ }^{11-16}$.

Currently there are no clinically useful screening tests to identify development of preeclampsia ${ }^{17}$. Altered lipid synthesis leading to decrease in PGI2:TXA2 ratio is also supposed to be an important way of pathogenesis in pregnancy induced hypertension ${ }^{18}$. 
There are also evidences suggesting that abnormal lipid metabolism in early pregnancy is associated with an increased risk of preeclampsia ${ }^{19}$.

The present study was aimed to investigate the relationship between early trimester serum lipid concentrations and risk of preeclampsia.

\section{Materials and Methods}

The study was conducted in department of Obstetrics and Gynecology, Queen Mary's Hospital, King George's Medical University, Lucknow for a period of one year in collaboration with the department of Pathology, King George's Medical University, and Lucknow.

With the approval of the institutional ethics committee and written informed consent from each woman, total 300 women between 20-35 years of age with 13-20 weeks of gestation were enrolled.

Women with history of essential hypertension, renal disease, epilepsy, diabetes or any other chronic or preexisting disease were excluded from the study.

All enrolled women were suggested to detailed medical, menstrual and obstetrical history followed by general, systemic and obstetrical examination along with all routine investigations.

$3 \mathrm{ml}$ of venous blood was collected for serum lipid profile estimation and test was done on same day. Serum lipid profile estimation was done by enzymatic method with the help of accurex diagnostic kit (manufactured by Accurex Biomedical PVT LTD, India) and the test was analyzed on Selectra-E random access analyzer (Merck).
Serum LDL cholesterol (LDL-C) was calculated by Frederickson-Friedwald's formula according to which LDL cholesterol $=$ Total cholesterol $-($ HDL cholesterol + VLDL cholesterol). VLDL cholesterol (VLDL-C) was calculated as 1/5 of Triglycerides (TG). Lipid profile

concentration was measured in milligram per deciliter $(\mathrm{mg} / \mathrm{dl})$. The selected subjects were followed for development of preeclampsia till delivery. Out of total 300 women 30 were lost follow up so only 270 women were followed till delivery.

Out of 270 women 58 women developed preeclampsia has taken as study group and 212 normotensive women has been taken as control group. Study group were divided as mild preeclampsia ( $\mathrm{BP} \geq 140 / 90$ to $<160 / 110 \mathrm{~mm} \mathrm{Hg}$ ) and severe preeclampsia ( $\mathrm{BP} \geq 160 / 110 \mathrm{mmHg})$.

\section{Statistical Analysis:}

The continuous data were summarized as mean and standard deviation while discrete (categorical) in numbers and percentage (\%). The continuous variables (Lipid profile: TC, TG, HDL-C, VLDL-C, LDL-C; Blood pressure: SBP and DBP) were compared by independent student's t test. The categorical variables were compared by chi-square $\left(\chi^{2}\right)$ test.

Univariate binary logistic regression analysis was used to find out lipid profile associated risk factors for preeclampsia. The adjusted multivariate logistic regression analysis was carried out further to find out the significant independent predictor for preeclampsia.

The univariate and multivariate analysis were done with adjusted demographic variables. The $\mathrm{p}<0.05$ was considered statistically significant. All analysis was carried out using SPSS 15.0 version. 


\section{Results}

The demographic characteristics of two groups were summarized in Table 1.

Table 1: Baseline subject characteristics

\begin{tabular}{|c|c|c|c|}
\hline Variable & $\begin{array}{c}\text { Normotensive } \\
(\mathrm{n}=\mathbf{2 1 2})\end{array}$ & $\begin{array}{l}\text { Preeclampsia } \\
\quad(n=58)\end{array}$ & p value \\
\hline Age(yrs) & $26.46 \pm 3.25$ & $27.10 \pm 3.73$ & 0.195 \\
\hline $\begin{array}{l}\text { Religion: } \\
\text { Hindu } \\
\text { Muslim }\end{array}$ & $\begin{array}{c}192(90.6 \%) \\
20(9.4 \%)\end{array}$ & $\begin{array}{c}53(91.4 \%) \\
5(8.6 \%)\end{array}$ & 0.850 \\
\hline $\begin{array}{c}\text { SES: } \\
\text { Lower } \\
\text { Middle } \\
\text { Higher }\end{array}$ & $\begin{array}{c}8(3.8 \%) \\
158(74.5 \%) \\
46(21.7 \%)\end{array}$ & $\begin{array}{c}4(6.9 \%) \\
39(67.2 \%) \\
15(25.9 \%)\end{array}$ & 0.432 \\
\hline $\begin{array}{c}\text { Diet: } \\
\text { Vegetarian } \\
\text { Non vegetarian }\end{array}$ & $\begin{array}{l}119(56.1 \%) \\
93(43.9 \%)\end{array}$ & $\begin{array}{l}26(44.8 \%) \\
32(55.2 \%)\end{array}$ & 0.126 \\
\hline $\begin{array}{l}\text { Blood Pressure }(\mathrm{BP}) \text { : } \\
\text { Systolic BP }(\mathrm{mm} \mathrm{Hg}) \\
\text { Diastolic BP }(\mathrm{mm} \mathrm{Hg})\end{array}$ & $\begin{array}{c}109.83 \pm 5.96 \\
80.29 \pm 6.26\end{array}$ & $\begin{array}{c}111.18 \pm 8.03 \\
81.34 \pm 9.21\end{array}$ & $\begin{array}{l}0.159 \\
0.132\end{array}$ \\
\hline
\end{tabular}

The baseline demographic characteristics of two groups were similar $(p>0.05)$ i.e. not differed statistically. The baseline blood pressures at the time of booking visit (13-20 weeks) were also not statistically different in both the groups.

Table 2: Lipid profile levels of preeclamptic and normotensive women

\begin{tabular}{|c|c|c|c|}
\hline Lipid profile & Normotensive & $\begin{array}{c}\text { Preeclampsia } \\
(\mathbf{n}=\mathbf{5 8})\end{array}$ & $\mathrm{p}<0.001$ \\
\hline TC & $164.65 \pm 18.63$ & $230.48 \pm 46.69$ & $\mathrm{p}<0.001$ \\
\hline TG & $155.22 \pm 22.31$ & $207.76 \pm 47.31$ & 0.007 \\
\hline HDL & $39.26 \pm 21.20$ & $31.33 \pm 11.81$ & $\mathrm{p}<0.001$ \\
\hline VLDL & $31.78 \pm 8.24$ & $42.50 \pm 11.93$ & $\mathrm{p}<0.001$ \\
\hline
\end{tabular}

TC: Total cholesterol, TG: Triglyceride, HDL: High density lipoprotein, VLDL: Very low density lipoprotein, LDL: Low density lipoprotein 
Table 2 showed that levels of all lipid profiles (TC, TG, VLDL-C and LDL-C) except HDL-C, were significantly ( $<<0.001$ ) higher in preeclamptic women than normotensive women. While preeclamptic women showed significant fall in High density lipoprotein cholesterol (HDL-C) level as compared to normal pregnant women.

Women who subsequently developed preeclampsia had $28.6 \%, 25.3 \%, 25.2 \%$ and $35.7 \%$ higher concentration of TC, TG, VLDL-C and LDL-C respectively than normotensive women. HDL-C concentration was $20.2 \%$ lower in preeclamptic women as compared with normotensive women $(\mathrm{p}=0.007)$.

Table 3: Lipid profile levels of mild and severe preeclamptic women

\begin{tabular}{|c|c|c|c|}
\hline Lipid profile & $\begin{array}{c}\text { Mild preeclamptic } \\
(\mathbf{n = 4 1 )}\end{array}$ & $\begin{array}{c}\text { Severe preeclamptic } \\
(\mathbf{n = 1 7})\end{array}$ & p value \\
\hline TC & $224.65 \pm 49.61$ & $244.54 \pm 36.25$ & $\mathrm{p}<0.001$ \\
\hline TG & $194.75 \pm 47.87$ & $239.10 \pm 27.64$ & 0.030 \\
\hline HDL & $35.40 \pm 11.45$ & $27.25 \pm 15.40$ & $\mathrm{p}<0.001$ \\
\hline VLDL & $38.71 \pm 8.44$ & $51.60 \pm 14.29$ & 0.364 \\
\hline LDL & $146.92 \pm 21.58$ & $149.38 \pm 17.23$ & \\
\hline
\end{tabular}

TC: Total cholesterol, TG: Triglyceride, HDL: High density lipoprotein, VLDL: Very low density lipoprotein, LDL: Low density lipoprotein

Further, comparing the levels of lipid profile between mild and severe preeclamptic women, the levels of TC, TG and VLDL$\mathrm{C}$ in severe preeclamptic women were also significantly $(\mathrm{p}<0.01$ or $\mathrm{p}<0.001)$ higher than mild preeclamptic women where as there was no significant difference in LDL-C level between both groups. While severe preeclamptic women showed significant fall in high density lipoprotein cholesterol (HDL-C) level as compared to mild preeclamptic women, (Table 3).

Table 4: Odds ratios (OR) and $95 \%$ confidence intervals (CI) of the association between preeclampsia risk and maternal serum lipid and lipoprotein concentrations

\begin{tabular}{|c|c|c|c|c|}
\hline Variables & $\begin{array}{c}\text { Unadjusted OR } \\
\mathbf{( 9 5 \%} \mathbf{C I})\end{array}$ & p value & $\begin{array}{c}\text { Adjusted OR } \\
\mathbf{( 9 5 \%} \text { CI) }\end{array}$ & p value \\
\hline TC & $2.13(1.09-7.18)$ & 0.041 & $2.09(1.16-6.19)$ & 0.045 \\
\hline TG & $3.06(0.94-9.07)$ & $\mathrm{p}<0.001$ & $2.96(1.04-8.45)$ & 0.021 \\
\hline HDL & $2.20(0.98-5.02)$ & 0.038 & $2.26(1.08-6.02)$ & 0.047 \\
\hline VLDL & $2.12(0.78-6.16)$ & 0.043 & $2.15(1.08-5.46)$ & $\mathrm{p}<0.001$ \\
\hline
\end{tabular}


TC: Total cholesterol, TG: Triglyceride, HDL: High density lipoprotein, VLDL: Very low density lipoprotein, LDL: Low density lipoprotein, ORs: odd Ratios

The lipid profile associated preeclampsia risk were evaluated by using univariate unadjusted and multivariate adjusted (adjusted for confounders age, parity, religion, SES and diet) logistic regression analysis and summarized in Table 4. Univariate unadjusted logistic regression analysis revealed that the higher lipid values of TC, TG, HDL-C, VLDL-C and LDL-C were significantly $(\mathrm{p}<0.001)$ associated with the risk of developing preeclampsia.

Further, adjusted multivariate logistic regression analysis confirmed $\mathrm{TC}(\mathrm{OR}=2.09,95 \% \mathrm{CI}=1.16-6.19, \mathrm{p}<0.045), \mathrm{TG}$ $(\mathrm{OR}=2.96,95 \% \mathrm{CI}=1.04-8.45, \mathrm{p}<0.001), \mathrm{HDL}-\mathrm{C}(\mathrm{OR}=2.26,95 \% \mathrm{CI}=1.08-6.02, \mathrm{p}<0.021) \mathrm{VLDL}-\mathrm{C}(\mathrm{OR}=2.15,95 \% \mathrm{CI}=1.08-$ 5.46, $\mathrm{p}<0.047)$ and LDL-C $(\mathrm{OR}=3.01,95 \% \mathrm{CI}=1.07-7.12, \mathrm{p}<0.001)$, the significant and independent risk factors for preeclampsia.

\section{Discussion}

In the present study, we observed an association between maternal early pregnancy dyslipidemia and the subsequent risk of preeclampsia. Pregnant women who subsequently developed preeclampsia had increased levels of total TC, TG, VLDL-C and LDL-C concentration as compared with pregnant women who remained normotensive. While preeclamptic women showed significant fall in high

density lipoprotein cholesterol (HDL-C) level as compared to normal pregnant women.

We observed that if TC, TG, VLDL-C and LDL-C levels are higher in early second trimester there was increased risk of developing preeclampsia and severity of preeclampsia was directly related to levels of total

cholesterol, triglycerides and VLDL-C which were statistically significant. Whereas LDL-C level was not significantly higher in severe preeclamptic group as compared with mild preeclamptic group. However we find a significant inverse relationship of HDL-C level with severity of preeclampsia.

Our results, when taken together with those of earlier prospective studies ${ }^{10,12,20-22} \quad$ indicate that dyslipidemia,particularly hypertriglyceridemia and elevated lipoprotein, precede the clinical manifestation of preeclampsia and thus may be of etiologic and

pathophysiologic importance in this relatively common complication of pregnancy.

The strength of our study was that we had adequate number of preeclampsia patients and control subjects to demonstrate statistically significant association and we used logistic regression to adjust for a number of confounders.

Several limitations in our study observed. First, variation in lipid measurement may have been introduced because we used non fasting blood samples because the study participants were pregnant, they were not asked to fast before blood was drawn.

However, the differences observed between fasting and nonfasting lipids are usually small. ${ }^{23,}{ }^{24}$ Second, a single measurement of blood samples may have resulted in some misclassification of maternal lipid profiles during pregnancy.

Longitudinal studies with serial measurements of maternal lipid and lipoprotein concentrations are needed to elucidate patterns of lipid changes and pathophysiologic consequences of such changes during pregnancy. 
The association between dyslipidemia and risk of preeclampsia is biologically plausible and is compatible with what is known about pathophysiology of preeclampsia.

Three hypothesized mechanism for dyslipidemia and preeclampsia association has been described. First, investigator noted that elevated plasma lipid and lipoprotein may induce endothelial dysfunction secondary to oxidative stress.

They also noted that dyslipidemia may impair trophoblast invasion thus contributing to a cascade of pathophysiologic events that lead to the development of preeclampsia ${ }^{6}$.

Second, mechanism is pathologic process of preeclampsia via dysregulation of lipoprotein lipase resulting in a dyslipidemic lipid profile. Enderssen et $\mathrm{al}^{25}$ and Lorentzen et $\mathrm{a}^{12}$ showed that sera from preeclamptic women had both a higher ratio of free fatty acids to albumin and increased lipolytic activity, resulting in enhanced endothelial uptake of free fatty acids, which are further esterified to triglycerides.

Third, possible mechanism may be via metabolic syndrome. Metabolic characteristic of insulin resistance syndrome namely hyperinsulinemia and hyperurecemia are also present in preeclampsia ${ }^{9}$.

Moreover, women with a history of preeclampsia, as compared with their BMI-matched counterparts without such a history, have higher circulating concentrations of fasting insulin, lipid, and inflammatory and coagulation factors years after delivery ${ }^{26}$.

Thus genetic and environmental factors that contribute to the pathogenesis of metabolic syndrome and related to vascular disorders may also be important in determining the occurrence of preeclampsia.

Estimation of maternal lipid profile in early second trimester may bring about early recognition of patients at risk of preeclampsia before the clinical symptoms and complications of preeclampsia appear for a better feto- maternal outcome. The findings from this study continue to support a role for dyslipidemia in preeclampsia. Prospective studies measuring lipid profiles throughout pregnancy and the postpartum period are needed to further our understanding of the importance of dyslipidemia in preeclampsia and its long term impact on the cardiovascular health of women.

Acknowledgement: We are grateful to the Uttar Pradesh Council of Science and Technology (UPCST) for providing research grant.

\section{Conflict of interest: None}

\section{Permission from IRB: Yes}

\section{References}

1. Ghulmiyyah L, Sibai B. Maternal mortality from preeclampsia/ eclampsia. Seminars in Perinatology. 2012; 36:56-59.

2. Moodley J. Maternal deaths associated with hypertensive disorders of pregnancy. A population-based study Hypertension in Pregnancy. 2004; 23:247-256.

3. Duley L. The global impact of pre-eclampsia and eclampsia. Seminars in Perinatology. 2009; 33:130-137.

4. WHO Recommendations for Prevention and Treatment of Preeclampsia and Eclampsia: WHO Department of Maternal and Child Health, Geneva, Switzerland. 2011.

5. Rao AK, Daniels K, El-Sayed YY, Moshesh MK, Caughey AB. Perinatal outcomes among Asian American and Pacific Islander women. Am J Obstet Gynecol. 2006;195: 834-838.

6. Lorentzen B, Henrisksen T. Plasma lipids and vascular dysfunction in preeclampsia. Semin Reprod Endocrinol. $1998 ; 16: 33-39$.

7. Dekker G, Sibai BM. Etiology and pathogenesis of preeclampsia: current concepts. Am J Obstet Gynecol. 1998;179:1359-1375. 
8. Sattar N, Bendomir A, Berry C, Shepherd J, Greer IA, Packard C. Lipoprotein subfraction concentrations in preeclampsia: pathogenic parallels to atherosclerosis. Obstet Gynecol.1997;89:403-408.

9. Kaaja R, Tikkanen MJ, Viinikka L, Ylikorkala O. Serum lipoproteins, insulin, and urinary prostanoid metabolites in normal and hypertensive pregnant women. Obstet Gynecol.1995;85:353-356.

10. Gratacos E, Casals E, Sanllehy C, Cararach V, Alonso PL, Fortuny A. Variation in lipid levels during pregnancy in women with different types of hypertension. Acta Obstet Gynecol Scand.1996;75: 896-901.

11. Ogura K, Miyatake T, Fukui O, Nakamura T, Kameda T, Yoshino G. Low-density lipoprotein particle diameter in normal pregnancy and preeclampsia. $J$ Atheroscler Thromb. 2002;9:42-47.

12. Lorentzen B, Drevon C, Endresen M, Henriksen T. Fatty acid pattern of esterified and free fatty acids in sera of women with normal and pre-eclamptic pregnancy. $\mathrm{Br} J$ Obstet Gynaecol.1995;102:530-537.

13. Hubel C, Mclaughlin M, Evans R, Hauth B, Sims C, Roberts J. Fasting serum triglycerides, free fatty acids, and malondialdehyde are increased in preeclampsia, are positively correlated, and decrease within 48 hours post partum. Am J Obstet Gynecol.1996;174:975-982.

14. Franz H, Wendler D. A controlled study of maternal serum concentrations of lipoproteins in pregnancy-induced hypertension. Arch Gynecol Obstet.1992;252:81-86.

15. Ware-Jauregui S, Sanchez SE, Zhang C, Laraburre G, King IB, Williams MA. Plasma lipid concentrations in preeclamptic and normotensive Peruvian women. Int $J$ Gynecol Obstet. 1999;67:147-155.

16. Roberts JM, Pearson G, Cutler J, Lindheimer $M$. Summary of the NHLBI Working Group on Research on Hypertension During Pregnancy. Hypertension. 2003;41:437-44
17. Caren G, Solomon, Seely EW. Preeclampsia searching for cause. New Eng J Med. 2004;350(7):641-42.

18. Robson SC. Hypertension and renal disease in pregnancy. $6^{\text {th }}$ edition. Edmonds DK. editor. In: Dewhurst's Textbook of Obstetrics and Gynaecology for postgraduates. Blackwell Science, New York; 1999. p $167-$ 69.

19. Enquobahrie DA, Williams MA, Butler CL, Frderick IO, Miller RS, Luthy DA. Maternal plasma lipid concentration in early pregnancy and risk of preeclampsia. Am J Hypertens. 2004;17(7):574-81.

20. Lorentzen B, Endresen M, Clausen T, Henriksen T. Fasting serum free fatty acids and triglycerides are increased before 20 weeks of gestation in women who later develop preeclampsia. Hypertens Pregnancy. 1994;13:103-109.

21. Clausen T, Djurovic S, Henriksen T. Dyslipidemia in early second trimester is mainly a feature of women with early onset pre-eclampsia. $\mathrm{Br} J$ Obstet Gynaecol. 2001;108:1081-1087.

22. Wladimiroff JW, Van den Elzen HJ, Cohen-Overbeek TE, De Bruijin AJ, Grobbee DE. Serum lipids in early pregnancy and risk of pre-eclampsia. Br JObstet Gynaecol. 1996;103:117-122.

23. Craig SR, Amin RV, Russell DW, Paradise NF. Blood cholesterol screening influence of fasting state on cholesterol results and management decisions. J Gen Intern Med. 2000;15:395-99.

24. Schaefer EJ, Audelin MC, McNamara JR, et al. Comparison of fasting and postprandial plasma lipoproteins in subjects with and without coronary heart disease. Am J Cardiol. 2001;88:1129-33.

25. Endresen MJ, Lorentzen B, Henriksen T. Increased lipolytic activity and high ratio of free fatty acids to albumin in sera from women with preeclampsia leads to 
triglyceride accumulation in cultured endothelial cells. $\mathrm{Am}$

J Obstet Gynecol. 1992;167:440-447.

26. Sattar N, Greer IA. Pregnancy complications and maternal cardiovascular risk: opportunities for intervention and screening. Br Med J. 2002; 325:157-160.
How to cite this article?

Singh U,Yadav S, Mehrotra S, Natu SM, Kumari K, Yadav YS. Serum Lipid Profile in Early Pregnancy as a Predictor of Preeclampsia. Int J Med Res Rev 2013;1(2):56-62. doi: 10.17511/ijmrr.2013.i02.03 